\title{
DESEMPENHO NO VESTIBULAR, BACKGROUND FAMILIAR E EVASÃO: EVIDÊNCIAS DA UFPE*
}

\author{
Breno SAMpaio $^{\dagger}$ \\ YONY SAMPAIO ${ }^{\ddagger}$ \\ Euler P. G. De Mello $§$ \\ Andrea S. Melo ${ }^{\mathbb{I}}$
}

\begin{abstract}
Resumo
Este artigo tem como objetivo compreender a decisão de evasão de estudantes universitários, assunto ainda pouco entendido no Brasil. Ênfase é dada à relação entre renda, desempenho no vestibular, evasão e a probabilidade de tentar nova carreira em novo vestibular. Atenção também é dada ao efeito escola pública e cursinho pré-vestibular. Os resultados mostram que renda tem papel fundamental não só por proporcionar aos mais ricos melhores condições de estudo (escolas privadas, cursinhos), mas também por possibilitar ao aluno maior oportunidade de escolha da carreira que melhor se adeque as suas aptidões, favorecendo assim a permanência da desigualdade.
\end{abstract}

Palavras-chave: Desempenho no Vestibular; Evasão Escolar; Ensino Superior, Desigualdade.

\begin{abstract}
The main objective of this paper is to understand university students' dropout decision, which is an area still not well studied in Brazil. Particular atention is given to the relationship between income, performance, dropout and the decision to re-take the exam in an attempt to switch careers. The effect of public schools and tutoring classes are also estimated. Results show that income not only provide the students with a better study environment (through private schools and tutoring classes) but also allow for the posibility of trying different careers until a better student-career match is made, favoring the persistence of inequality.
\end{abstract}

Palavras-chave: College Entrance Test Scores; Higher Education, Inequality; Student drop-out.

JEL classification: I21, J24, O15

\footnotetext{
* As opiniões expressas nesse artigo são de inteira responsabilidade dos autores e não necessariamente refletem a opinião do Banco Central do Brasil. Erros remanescentes são de exclusiva responsabilidade dos autores.

${ }^{\dagger}$ University of Illinois at Urbana Champaign, email: sampaio2@illinois.edu.

‡ Universidade Federal de Pernambuco, email: sampyony@yahoo.com.br.

$\S$ Banco Central do Brasil e University of Illinois at Urbana Champaign, email: goncalv1@illinois.edu.

II Universidade Federal de Pernambuco, email: andrea.samelo@ufpe.br.
} 


\section{Introdução}

A evasão nas universidades públicas constitui-se um problema tanto para os estudantes como para as instituições. Para o individuo, pode representar o fim de aspirações de adquirir um grau universitário, com possíveis repercussões sobre o fluxo futuro de rendimentos. Para as instituições, tem um custo elevado, tanto pelo desperdício dos recursos gastos como pelo custo de oportunidade da vaga deixada ociosa. Em conseqüência, o melhor conhecimento do perfil dos estudantes que optam pela evasão mostra-se de extrema importância por permitir o delineamento de políticas visando melhor aproveitamento dos recursos desperdiçados.

A evasão nas universidades públicas federais brasileiras apresenta possivelmente aspectos que distinguem este fenômeno do que se observa em alguns outros países e nas universidades privadas. Como o ensino público é gratuito, a manutenção da matrícula vínculo não tem custo para o estudante embora apresente os mesmos custos que os da evasão para as universidades. Em consequência, apresentam-se duas situações bem distintas: a de um aluno que reconhecendo uma escolha equivocada ou a impossibilidade de continuar abandona o curso para tentar novo vestibular e a de um aluno que ingressa no mercado de trabalho, deixa de frequentar a universidade, mas mantém a matrícula por vários anos, ocupando a vaga. Quando o ensino é pago, a manutenção da matrícula tem um custo e o aluno opta pela evasão, e assim os dois tipos de alunos apresentam-se como similares.

Esta distinção pode inverter o sinal de alguns determinantes. Por exemplo, encontra-se na literatura que a evasão é negativamente correlacionada com a renda dos pais, o que pode ser explicado, dentre outras razões, pela atração do mercado de trabalho que incide mais quanto menor a renda; mas caso a razão do abandono seja o desencanto com o curso e a tentativa de ingresso em um outro, a evasão teoricamente deveria afetar em maior magnitude os mais ricos que podem arcar com um período de estudo preparatório para tentar um outro vestibular, assim como arcar com aulas particulares (cursinhos) aumentando a probabilidade de sucesso no vestibular. Neste exemplo, quanto menor a renda, em princípio, mais difícil se torna abandonar o curso pelo custo de ingresso em um outro. Dito de outra forma, mesmo que a evasão dos mais pobres seja dada pela atração do mercado de trabalho, pode ser o caso de a proporção dos mais ricos que se evadem para tentar um novo curso ser relativamente maior que a proporção dos mais pobres evadidos, o que faz com que a relação renda-evasão se torne negativa.

Ao lado da renda, o desempenho no vestibular é outro indicador da capacidade de sucesso em um outro vestibular. Nesse sentido, suponha a existência de dois alunos idênticos em termos de background familiar, habilidade, etc., porém, um apresenta alta nota de entrada e outro apresenta baixa nota de entrada para o mesmo curso na universidade. Suponha também que, após melhor conhecimento do curso, uma vez que as aulas são iniciadas, ambos apresentem mesmo nível de desagrado quanto à escolha da carreira feita prévestibular. Nesse sentido, um elevado desempenho no vestibular, se este é um indicador de bom desempenho em novo vestibular do ponto de vista do aluno, deve "favorecer" a evasão do aluno que entrou com maior nota. No caso, o aluno que entrou com nota menor leva em consideração sua probabilidade de ingressar em outro curso num novo vestibular e, ceteris paribus, deve evadir-se, em média, com menor probabilidade. Se este argumento é válido, 
então a correlação entre nota de entrada e evasão pode ser positiva, o que contradiz resultados anteriores apresentados na literatura (Ashenfelter \& Rouse 1998, Eckstein \& Wolpin 1999, Arulampalam et al. 2004, Lassibille \& Gómez 2008, Murtaught et al. 1999, Bradley \& Lenton 2007).

Outra variável importante para compreender o perfil dos alunos evadidos é o desempenho no curso universitário. Esta variável, por indicar a adaptabilidade do aluno ao curso e sua capacitação para acompanhá-lo deve, em princípio, apresentar correlação inversa com a evasão quando se controlando pela nota de entrada.

Este artigo, portanto, tem como objetivo buscar melhor compreensão de importante evento cuja compreensão é ainda pouco limitada na literatura nacional, ${ }^{1}$ porém de extrema relevância para o desenvolvimento do país, que é a evasão de alunos universitários. Maior ênfase é dada à relação entre renda e evasão e à relação entre nota de entrada no vestibular e evasão, tema bastante estudado na literatura internacional. ${ }^{2}$ Atenção também é dada a alguns determinantes do sucesso no exame do vestibular, como o efeito da escola pública e de aulas particulares (cursinhos), que são bastante populares entre alunos oriundos de famílias de maior renda.

O artigo contribui não só por traçar o perfil de alunos cuja probabilidade de evasão parece maior, mas também levanta importantes evidências a respeito da desigualdade de oportunidade que paira sobre o sistema educacional brasileiro, i.e., as barreiras que alunos oriundos de famílias de baixa renda tem de enfrentar para terem acesso ao ensino superior. Por um lado, alunos com maior renda tanto estudam em escolas privadas como têm acesso a cursinhos de matérias isoladas (o efeito de ambos no desempenho dos alunos no vestibular será discutido em breve). Por outro lado, os resultados mostram que apesar da evasão ser maior nos cursos cuja nota de entrada é menor, uma vez que efeitos fixos para os cursos são introduzidos na equação, o resultado se inverte, i.e., os melhores alunos de cada curso evadem-se em maior proporção em relação aos alunos que ingressaram com pior desempenho.

Uma hipótese para tal resultado é que, dado o reconhecimento de escolha da carreira equivocada, alunos com maior renda e (em consequência) melhor desempenho, estão optando pela evasão não pela escolha da entrada no mercado de trabalho, mas sim pela oportunidade que lhes é dada (através do suporte familiar) de tentar uma nova carreira. Nesse caso, se for assumido que um melhor matching com a carreira tem efeito positivo nos rendimentos futuros, alunos de famílias mais ricas têm, além de maior probabilidade de ingresso no ensino superior (via melhor background familiar, escola privada, cursinhos), maior oportunidade quanto ao encontro da carreira que melhor se adeque a suas aptidões.

Um resultado que corrobora a hipótese levantada acima é que ao se observar as características dos alunos que prestam vestibular no período seguinte a decisão de evasão, estes apresentam altas taxas de frequência em cursinhos

\footnotetext{
${ }^{1}$ A literatura no Brasil tem se focado basicamente em problemas que dizem respeito ao ensino primário e secundário. Ver, por exemplo, Veloso et al. (2009) sobre educação básica no Brasil e Cavalcanti et al. (2010) sobre determinantes do desempenho no vestibular. Ênfase também tem sido dada ao mercado de trabalho, como contribuições na área de retornos à educação (Resende 2006), assim como relações entre variáveis de curso/universidade e renda (por exemplo, Curi \& de Menezes-Filho (2006) analisam a correlação entre desempenho e renda).

${ }^{2}$ Ver Rothstein (2004), por exemplo, sobre relação entre nota no exame de entrada (SAT) e desempenho acadêmico em universidades americanas.
} 
pré-vestibulares além de terem, em comparação aos que se evadiram mas não são observados no vestibular seguinte, maior desempenho no primeiro vestibular e maior renda. Este resultado tem implicações políticas importantes. A idéia tradicional da evasão dos que têm desempenho pior reforça a necessidade de disciplinas de nivelamento, para suprir as carências do ensino médio; isso ainda pode ser válido em alguns casos. Mas o resultado da evasão dos melhores aponta para caminhos que passam pela flexibilização curricular ou das transferências internas, minimizando o custo para o aluno de um novo vestibular.

$\mathrm{Na}$ rigidez curricular prevalecente no Brasil, as transferências permitem ao aluno uma escolha de curso que melhor se adeque a suas aptidões; mas, no ensino americano, por exemplo, a flexibilidade curricular permite que, independentemente do curso, o aluno escolha disciplinas em acordo com seus interesses e aptidões. Outra observação importante é quanto à gratuidade da universidade. Se paga, o aluno mais fraco tem maior probabilidade de evasão uma vez que este permanece maior tempo, em media, na universidade, o que representaria maiores custos. Também o aluno mais pobre terá alto custo e a opção de ingressar no mercado de trabalho se torna mais atrativa.

A melhor compreensão de mecanismos que tendem a favorecer a manutenção de uma desigualdade ineficiente é de suma importância visto que o Brasil além de ser um dos paises mais desiguais do mundo e também um dos que apresenta menores taxas de mobilidade social (Bourguignon et al. 2007, Ferreira \& Veloso 2006).

Este trabalho apresenta cinco seções. Após esta breve introdução, na segunda seção é feita revisão da literatura sobre evasão. A base de dados e o modelo a ser estimado são apresentados na terceira seção. Na quarta seção encontram-se os resultados e a discussão. Por fim, na quinta seção são discutidas as implicações políticas dos resultados apresentados e as principais conclusões.

\section{Revisão da Literatura}

A evasão escolar pode decorrer de duas causas inter-relacionadas: da falta de interesse e da impossibilidade de continuar os estudos. A falta de interesse pode ter vários determinantes, atenuantes e reforçadores. A falta de conhecimento da área de estudos pode levar muitos estudantes a não se identificarem com a mesma; o desinteresse pelo estudo pode decorrer também da falta de perspectiva sobre os ganhos advindos com o aumento da escolaridade e obtenção de diplomas. Um reforçador da falta de interesse pode vir da falta de percepção ou orientação dos pais e de uma renda elevada que facilita o prolongamento da vida escolar e a busca de uma área de maior interesse; ao contrário, uma renda baixa pode fazer com que os alunos se atrelem às oportunidades; uma maior educação dos pais pode facilitar um maior conhecimento da área, mas aumenta a renda e pode permitir um tempo de decisão maior para escolha da carreira.

A impossibilidade pode ter várias razões: a dificuldade dos estudos, reforçada por reprovações; a baixa renda, antecipando o ingresso no mercado de trabalho; a idade, que tanto situa o aluno fora da faixa etária normal como reforça a atração do mercado de trabalho; o estado civil, esperando-se que os casados sejam mais inclinados pelo mercado de trabalho; o gênero, sendo a 
presença dos homens maior no mercado assim como a cobrança pela geração de renda; a falta de escolas. As duas causas são inter-relacionadas: a falta de motivação, por exemplo, pode decorrer da dificuldade de acompanhar o curso.

Uma outra forma de colocar a questão busca sustentação da teoria do capital humano (Becker 1964). O aluno prossegue nos estudos enquanto o fluxo descontado de retorno à educação for maior ou igual que o custo do investimento, dada a informação disponível. Continua estudando desde que o valor presente do retorno à educação seja maior ou igual ao custo do investimento que inclui a renda alternativa e os custos de manutenção, assumindo que a educação é gratuita. Abandona quando o ganho da evasão supera os custos.

Há duas situações distintas. Estudantes de famílias com menor renda podem ser atraídos pelo mercado de trabalho, avaliando que os ganhos com o emprego, dado o custo de manutenção, elevam o valor presente do fluxo líquido de renda; abandonam o curso, mas mantém-se matriculados, como uma opção para avaliações futuras quanto ao abandono ou retomada do curso. Estudantes de famílias com maior renda podem ter expectativa de uma renda maior ao trocar de curso e tem custo relativo de manutenção menor, decidindo-se pelo abandono rápido.

Assim, estudantes oriundos de famílias com maior renda, inclusive com habilidade maior (em decorrência do efeito educação/renda familiar), podem ter expectativa de renda maior ao trocar de curso, e custo menor de manutenção, ao residir com a família e ter mais facilidade para custear os estudos necessários para o habilitar para ingressar em novo curso. Já os alunos de famílias de menor renda, podem ter expectativa de retorno futuro menor, tem custo de manutenção que pesa para a família, agravado se vierem de outras cidades, e maior dificuldade para incorrer nas despesas para mudança de curso.

Em síntese, as duas abordagens, sob a ótica do ensino universitário gratuito, destacam a importância da renda em determinar a evasão ou a matrícula continuada sem cursar efetivamente, como estratégia de adiamento da decisão (a qual é antecipada quando o ensino é pago).

A outra variável fundamental, ao lado da renda, é o desempenho no vestibular, representado usualmente pelo argumento de classificação. Esse argumento representa um indicador das possibilidades de ingresso em um outro vestibular, caso se decida pela evasão e troca por um outro curso. Os menos confiantes, com desempenho mais baixo, podem optar por não arriscar e concluir o curso mesmo sem manter o mesmo entusiasmo. A decisão por continuar é reforçada mais se ao lado do baixo desempenho se aliar uma renda familiar mais baixa, que retira a condição de novos investimentos em outra carreira, mesmo que o fluxo descontado de retorno à educação seja positivo. ${ }^{3}$ É o caso da falta de liquidez limitando as oportunidades.

O desempenho no curso, uma vez ingressado na universidade, reflete tanto o interesse e a adaptação ao curso como a capacitação necessária para acompanhá-lo. Dessa forma, um bom desempenho reforça a adequação. Ou, dito de outra forma, os que mostram capacitação insuficiente ou descobrem a pouca empatia com o curso, devem apresentar desempenho mais baixo, indicador de uma possível evasão.

\footnotetext{
${ }^{3}$ Desempenho no vestibular e renda são correlacionados via o efeito direto da renda e via escola pública, dado que pais mais ricos colocam seus filhos em escolas privadas. Ver Guimarães \& Sampaio (2007), Sampaio \& Guimarães (2009) e Cavalcanti et al. (2007) para uma discussão mais elaborada sobre o efeito renda e o efeito escola pública.
} 
Tanto o retorno como os custos são afetados por características pessoais, sociais e da educação anterior. A literatura mais antiga destaca o desempenho nos estudos anteriores (por exemplo, a nota em testes de ingresso na universidade) e o custo do estudo, no caso de universidades pagas (Blanchfield 1972). ${ }^{4}$ Mas como argumentado, se o ensino é gratuito, a decisão passa a ser condicionada fundamentalmente ao desempenho e à renda.

As duas visões são, em certo sentido, equivalentes. Uma destaca mais o aspecto do cálculo econômico e a outra explicita a psicologia que embasa o cálculo econômico. As duas causas principais de uma e outra - motivação e impossibilidade ou retorno e custo - são interdependentes. As proxies usadas são idênticas. Destacam-se as seguintes variáveis: desempenho anterior e nota de ingresso; tipo de escola frequentada; características pessoais (idade, gênero, etnia, local de residência); características dos pais (renda, educação); características do mercado de trabalho; postura da instituição em relação à evasão. Estas variáveis devem ser incluídas como controle, embora a ênfase desse trabalho encontre-se nos dois determinantes principais: desempenho e renda.

Os diversos trabalhos encontram que quanto maior o desempenho escolar anterior e a nota de ingresso menor a probabilidade de evasão (Blanchfield 1972, Arulampalam et al. 2004, Lassibille \& Gómez 2008, Murtaught et al. 1999, Bradley \& Lenton 2007). Como visto, o desempenho anterior aumenta a probabilidade de sucesso (e de retorno), aumenta a probabilidade de um maior conhecimento das perspectivas da carreira e diminui os riscos e custos do insucesso. Mas, como argumentado, quando o ensino é gratuito e, dadas as razões para evasão, o sinal desta variável pode inclusive aparecer trocado. Alunos com notas mais elevadas podem trocar de curso com mais facilidade. Políticas que facilitem as transferências internas seriam apropriadas.

O tipo de escola frequentada, no caso pública e privada, atua de forma indireta, via a qualidade da escola e o conhecimento e informação que confere. No estudo de Arulampalam et al. (2004) de escolas de medicina, a evasão era maior para os oriundos de escolas públicas, resultado determinado pela qualidade e relacionado ao desempenho do aluno. Esta variável é mais relevante no Brasil, dada a maior diferença qualitativa por tipo de escola. Alunos de escolas públicas podem ter menor probabilidade de trocar de curso e se evadir menos, em cursos com menor evasão. Mas, se a atração do mercado de trabalho for a razão da evasão, podem se evadir mais.

Dentre as características pessoais destaca-se a idade de ingresso, o gênero e a etnia. Os diversos estudos encontram que a evasão é maior entre os alunos que ingressaram mais velhos na universidade (Arulampalam et al. 2004, Lassibille \& Gómez 2008, Murtaught et al. 1999). Visto pela teoria do capital humano, o custo de oportunidade dos mais velhos é maior; de outro lado, tanto a motivação pode ser menor e a inadequação de faixa etária maior como a dificuldade nos estudos tende a ser maior. Quanto ao gênero, a evasão é maior entre os homens (Arulampalam et al. 2004, Lassibille \& Gómez 2008), principalmente em cursos técnicos (Lassibille \& Gómez 2008). Em relação à etnia, Murtaught et al. (1999), trabalhando com dados dos Estados Unidos, encontram maior evasão entre os afros-descendentes; Bradley \& Lenton (2007)

\footnotetext{
${ }^{4}$ Os trabalhos no Brasil concentram-se nos determinantes do desempenho de estudantes no vestibular (ver Emilio et al. (2004) e Guimarães \& Sampaio (2011)) assim como na universidade (ver Cavalcanti et al. (2007)).
} 
encontram evasão maior para negros e hispânicos. A explicação decorre do menor custo de oportunidade para estas minorias, incluindo discriminação no mercado de trabalho. A etnia apresenta correlação com a renda dos pais, afetando tanto as expectativas de retorno como o custo de oportunidade.

Entre as características dos pais, estuda-se a educação e a renda. Arulampalam et al. (2004) construíram uma variável classe social e encontram fraca relação com a evasão. Bradley \& Lenton (2007), Lassibille \& Gómez (2008) e Di Pietro (2004) encontram maior evasão quando os pais são menos educados. A atração do mercado de trabalho deve ser maior com pais de menor renda e menos educados. Mas, como argumentado, quando o ensino é gratuito, a matrícula é mantida, mesmo sem frequência regular. A evasão para mudança de curso deve ser maior para estudantes com pais com renda e educação maiores, motivada pela tentativa de ingresso em outro curso.

Características do mercado de trabalho afetam a evasão. A experiência indica que alunos em cursos com boa inserção no mercado apresentam maior evasão. Bradley \& Lenton (2007) encontram que um mercado de trabalho ativo favorece a evasão; quando a economia apresenta baixo crescimento, a evasão diminui. No Brasil, carreiras com fortes restrições ao exercício da profissão sem diploma, como medicina e direito, devem apresentar menor evasão que carreiras onde prevalece a experiência e a competência como em ciência da computação e nas áreas humanas e sociais.

O custo do ensino é outra variável destacada. Sabe-se que quanto maior o custo maior a evasão, uma interpretação direta do custo de oportunidade da teoria do capital humano. Diversos trabalhos têm encontrado que a oferta de bolsas de estudo e outras formas de financiamento diminuem a evasão (Blanchfield 1972, DesJardins et al. 1999, Lassibille \& Gómez 2008). No Brasil esta é uma realidade cruel: nas universidades públicas os alunos mantêm a matrícula sem frequentar, retardando a evasão, com custo maior para a instituição; nas universidades privadas, o custo faz com os alunos se evadam mais cedo. A diferença fundamental aparece entre a evasão e a retenção.

Alguns poucos trabalhos destacam o papel da instituição. A evasão é menor para universidades com maior preparo acadêmico e maior inserção social (Arulampalam et al. 2004, Lassibille \& Gómez 2008). A instituição, basicamente, reforça as motivações, aumenta a probabilidade de sucesso e o fluxo futuro de retorno. Murtaught et al. (1999) encontram que um trabalho de orientação e acompanhamento dos estudantes reduz a taxa de evasão. Apesar da importância desta constatação, esta é uma variável não disponível na maioria dos bancos de dados. Pode ser intuída, de forma indireta pelo prestigio do curso. Evasão menor em cursos com maiores oportunidades, como medicina, e menor em outros com menor fluxo de retorno médio.

\section{Dados e Estimação}

\subsection{Dados}

Os dados foram disponibilizados pela Comissão de Processos Seletivos e Treinamentos - COVEST-COPSET - e pelo Núcleo de Tecnologia da Informação NTI - da Universidade Federal de Pernambuco (UFPE). A COVEST-COPSET forneceu dados referentes ao questionário sócio-econômico coletado no período em que os estudantes estavam prestando vestibular assim como a nota final de entrada dos estudantes aprovados na universidade. Os dados se refe- 
rem aos vestibulares de 2003 e 2004 em que 53.667 e 50.160 estudantes, respectivamente, estavam prestando vestibular. O NTI forneceu dados referentes ao desempenho acadêmico dos estudantes em cada período da universidade assim como dos que optaram pela evasão. O número total de aprovados em 2003 e 2004 foi de 3.975 e 4.000, respectivamente. A evasão, neste trabalho, representa os alunos que ingressaram em 2003 e 2004 e que, ao longo período de análise (que inclui dois anos após ingresso), deixam de frequentar a universidade.

\subsection{Estatísticas Descritivas}

A Tabela 1 abaixo apresenta estatísticas descritivas das variáveis utilizadas. Note que de um total de 7.975 indivíduos que entraram nos anos de 2003 e 2004, ao se excluir os valores com informação incompleta (missings), obtém-se uma base com 7.582 observações. Destes, aproximadamente $30 \%$ abandonaram o curso nos primeiros dois anos, embora cerca de $85 \%$ do total de indivíduos analisados tenham afirmado estar decidido quanto ao curso ao prestarem vestibular.

Apesar da idade média dos indivíduos analisados ser de 20 anos, 60\% dos indivíduos possuem até 19 anos. ${ }^{5}$ Em sua maioria, os indivíduos são (95\%) solteiros, possuem pelo menos um dos pais com curso superior completo (53\%), moram na região metropolitana do Recife (91\%), possuem renda familiar de até 15 salários mínimos (79\%) e fizeram cursinho preparatório para vestibular $(64 \%) .16 \%$ dos alunos cursou o ensino fundamental em escolas públicas e $25 \%$, o ensino médio. A nota de entrada pode tomar valores entre 0 e 10 , sendo a média cerca de 6 e a menor nota 2,63.

No que tange o número de vestibulares prestados na UFPE em anos anteriores, por volta de $70 \%$ da amostra fez no máximo duas provas de vestibular antes de ingressar na Universidade Federal de Pernambuco e pouco mais de $40 \%$ ingressou na universidade na segunda entrada (Há cursos que disponibilizam duas entradas, no primeiro e segundo semestres acadêmicos, respectivamente. Os estudantes são alocados nas entradas em função da nota final do aluno no vestibular e da escolha especifica de cada aluno. Ou seja, alunos com melhor desempenho têm acesso garantido à primeira entrada, podendo, no entanto, escolher voluntariamente entrar na segunda entrada. Já alunos com pior desempenho são automaticamente alocados na segunda entrada, mesmo que tenha selecionado como prioridade a primeira entrada).

Na Tabela 1 abaixo apresentam-se os índices de evasão por curso em ordem decrescente. O curso com maior evasão é Desenho e Plástica, onde pouco mais de $70 \%$ dos alunos optaram pela evasão. Por outro lado, o curso com menor evasão é Medicina, onde somente 1.5\% dos alunos se evadiram. Podese observar também que os cursos da área de saúde encontram-se entre os com menores índices de evasão.

\subsection{Estimação}

Neste artigo busca-se estimar a correlação entre nota de entrada no vestibular, renda familiar e educação dos pais sobre a probabilidade de evasão do ensino superior usando dados da Universidade Federal de Pernambuco (UFPE). Mais especificamente, estima-se a seguinte equação:

\footnotetext{
${ }^{5} \mathrm{O}$ indivíduo mais velho a entrar na UFPE nesta amostra possuía 72 anos e o mais novo 15.
} 


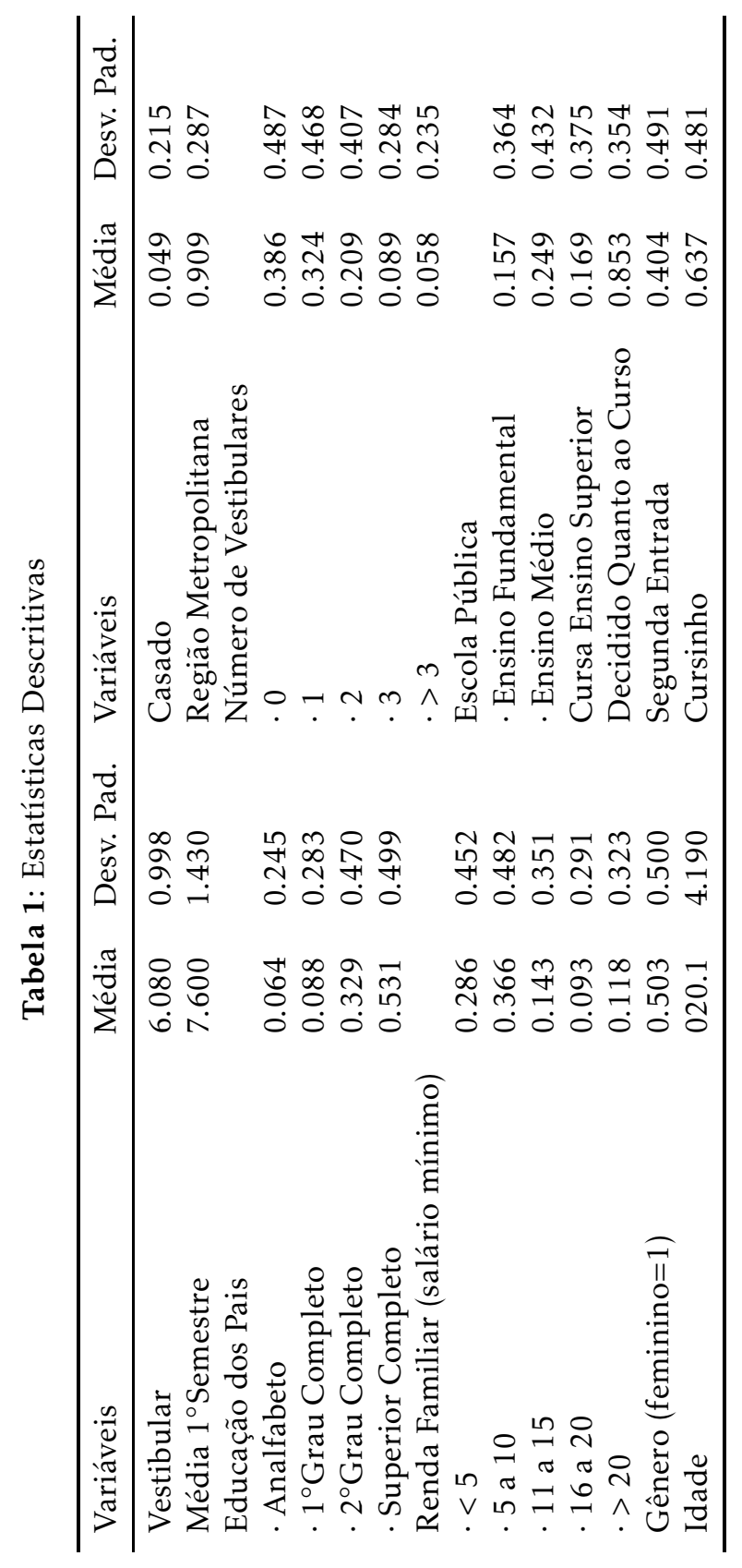


Tabela 2: Evasão por Curso

\begin{tabular}{lrlc}
\hline Curso & Evasão Curso & Evasão \\
\hline Desenho e Plástica - Licenciatura & .711 & Engenharia Biomédica & .325 \\
Matemática - Bacharelado & .667 & Comunicação Social - Public. e Propag. & .316 \\
Física - Licenciatura & .635 & Educação Artística - Artes Plásticas & .316 \\
Engenharia Cartográfica & .574 & Comunicação Social - Jornalismo & .297 \\
Química - Licenciatura & .549 & Ciências Biológicas - Bacharelado & .293 \\
Educação Artística - Artes Cênicas & .535 & Comunicação Social - Radialismo e TV & .291 \\
Ciências Sociais - Bacharelado & .530 & Ciências Biológicas - Ciências Ambientais & .280 \\
Matemática - Licenciatura & .524 & Engenharia de Computação & .280 \\
Filosofia & .516 & Administração & .274 \\
Estatística & .511 & Arquitetura e Urbanismo & .270 \\
Ciências Sociais & .508 & Geografia - Licenciatura & .252 \\
Física - Bacharelado & .481 & Educação Física & .242 \\
Geologia & .464 & Biblioteconomia & .227 \\
Ciências Econômicas & .464 & Pedagogia & .219 \\
Música - Instrumento & .455 & Serviço Social & .214 \\
Engenharia Elétrica - Eletrotécnica & .431 & Ciências Biológicas - Licenciatura & .200 \\
Engenharia de Minas & .426 & Secretariado & .200 \\
Engenharia Civil & .422 & Ciências da Computação & .197 \\
Química - Bacharelado & .405 & Biomedicina & .181 \\
Química Industrial & .400 & Farmácia & .181 \\
Geografia - Bacharelado & .396 & Odontologia & .171 \\
Ciências Contábeis & .385 & Fisioterapia & .165 \\
Engenharia Química & .381 & Turismo & .159 \\
Engenharia Mecânica & .378 & Direito & .148 \\
História & .365 & Terapia Ocupacional \\
Engenharia de Produção & .365 & Nutrição & .143 \\
Música - Licenciatura & .360 & Psicologia & .139 \\
Letras & .352 & Enfermagem & .128 \\
Engenharia Elétrica - Eletrônica & .346 & Fonoaudiologia \\
Hotelaria & .342 & Medicina & .015 \\
\hline & & & .122 \\
\hline
\end{tabular}

$$
P\left(D R O P_{i c}=1 \mid E N T_{i c}, X_{i c}\right)=G\left(\beta+\rho E N T_{i c}+X_{i c} \Theta+\mu_{c}\right)
$$

onde $D R O P_{i c}$ é uma variável dicotômica que assume valor igual a um para o estudante $i$ do curso $c$ que opta pela evasão e, caso contrário, valor igual a zero; $X_{i c}$ é um vetor de características que inclui renda e educação dos pais, ${ }^{6}$ assim como gênero, idade, estado civil, etc., e $\mu_{c}$ é um efeito fixo para o curso em que o aluno está matriculado.

Optou-se por utilizar o modelo probit, um caso particular de modelos para variáveis dependentes dicotômicas, o qual supõe que a distribuição dos erros seja a Gaussiana. Dentre as vantagens do modelo probit está o fato dele restringir as probabilidades ao intervalo $[0,1]$ e relaxar a hipótese do efeito das variáveis explicativas ser linear. Quanto a esse efeito, em um modelo probit, dada uma variação em uma das variáveis independentes, seu efeito é menor quanto mais nas caudas da distribuição da variável dependente se estiver.

Nas tabelas apresentadas na próxima seção, toma-se o cuidado de reportar os efeitos marginais ao invés dos coeficientes de forma a tornar a interpretação dos resultados mais direta. ${ }^{7}$ Dado a natureza não linear do modelo probit, o coeficiente estimado de uma interação não necessariamente mede o efeito real

\footnotetext{
${ }^{6}$ Define-se educação dos pais como o máximo entre o nível de educação da mãe e do pai.

${ }^{7}$ Para que isso seja possível, é necessário que se escolha um ponto em particular uma vez que o modelo é não-linear. Foi escolhido tal ponto como sendo a média amostral, procedimento usualmente empregado na literatura.
} 
das variáveis interadas (Ai 2003). Nesse caso, o efeito total da interação pode ser obtido pela seguinte fórmula:

$$
\frac{\Delta^{2} \Phi(z)}{\Delta x_{1} \Delta x_{2}}=\Phi\left(\beta_{1}+\beta_{2}+\beta_{12}+X \beta\right)-\Phi\left(\beta_{1}+X \beta\right)-\Phi\left(\beta_{2}+X \beta\right)+\Phi(X \beta),
$$

onde $x_{1}$ e $x_{2}$ são variáveis dicotômicas e o efeito de interesse é dado pela interação de ambas. O erro padrão da interação é obtido através do método delta e, para o caso de duas variáveis dummies interadas, dado pela seguinte formula:

$$
\frac{\partial}{\partial \beta^{\prime}}\left[\frac{\Delta^{2} \Phi(z)}{\Delta x_{1} \Delta x_{2}}\right] \hat{\Omega}_{\beta} \frac{\partial}{\partial \beta}\left[\frac{\Delta^{2} \Phi(z)}{\Delta x_{1} \Delta x_{2}}\right]
$$

onde $\hat{\Omega}_{\beta}$ é um estimador consistente para a covariância de $\hat{\beta} .{ }^{8}$ Um outro ponto importante é que, uma vez que a base de dados contém informações sobre diversos indivíduos, opta-se por divulgar os desvios-padrão robustos a heteroscedasticidade.

É também analisado o efeito de se estudar em escolas privadas ou públicas e o efeito de participar de cursinhos pré-vestibulares. O problema principal em se estimar ambos os efeitos via OLS, onde a variável de interesse seria um indicador identificando os alunos matrículas nas escolas públicas ou nos cursinhos pré-vestibulares, é que esta variável possivelmente teria correlação com o termo de erro, gerando problemas de endogeneidade. Por exemplo, pais podem enviar os filhos menos hábeis para escolas públicas e investir nos mais hábeis os enviando as escolas privadas. Porém, podem também tentar compensar as diferenças inatas de habilidade mandando os menos hábeis para escolas privadas e os mais hábeis para escolas públicas. ${ }^{9}$

Ou seja, de forma geral, a habilidade e diversas outras variáveis correlacionadas com a decisão dos estudantes de participar de cursinhos pré-vestibulares ou de ingressarem em escolas públicas/privadas não são observadas e, portanto, fazem com que a estimação OLS seja viesada. Para estimar corretamente os efeitos de interesse seria necessário a disponibilidade de variáveis instrumentais que afetassem de forma exógena a probabilidade de ingresso em escolas públicas e cursinhos, porém que fossem não correlacionadas com variáveis não observáveis do estudante. Como as variáveis instrumentais utilizadas na literatura americana para avaliar escolas católicas são bastante contestáveis, ${ }^{10}$ optou-se neste trabalho pela abordagem elaborada por Altonji, E. \& Taber (2005).

O procedimento desenvolvido por Altonji, E. \& Taber (2005) permite avaliar o tamanho potencial do viés causado por variáveis não observáveis. Para tanto, os autores propõem a idéia de que a "seleção nas observáveis tem o mesmo efeito que a seleção nas não observáveis", que é equivalente a

$$
\frac{\operatorname{Cov}(u, E)}{\operatorname{Var}(u)}=\frac{\operatorname{Cov}(\beta X, E)}{\operatorname{Var}(\beta X)}
$$

onde $E$ é a variável dummy endógena, $X$ é um vetor de características observáveis e $u$ é um termo de erro possivelmente correlacionado com $E$. O viés

\footnotetext{
${ }^{8}$ Ver Ai (2003) para mais detalhes.

${ }^{9}$ Ver Behrman et al. (1982) e Behrman et al. (1994).

${ }^{10}$ Ver Altonji, Elder \& Taber (2005).
} 
incorrido na estimação $\operatorname{OLS}, \operatorname{Cov}(u, \tilde{E}) / \operatorname{Var}(\tilde{E})$, onde o til representa o resíduo da regressão de $E$ em $X$, pode ser estimado da seguinte forma

$$
\begin{aligned}
\frac{\operatorname{Cov}(u, \tilde{E})}{\operatorname{Var}(\tilde{E})} & =\frac{\operatorname{Cov}(u, E)}{\operatorname{Var}(\tilde{E})} \\
& =\frac{\operatorname{Cov}(u, E)}{\operatorname{Cov}(\beta X, E)} \frac{\operatorname{Var}(\beta X)}{\operatorname{Var}(u)} \frac{\operatorname{Cov}(\beta X, E)}{\operatorname{Var}(\beta X)} \frac{\operatorname{Var}(u)}{\operatorname{Var}(\tilde{E})} \\
& =\frac{\operatorname{Cov}(\beta X, E)}{\operatorname{Var}(\beta X)} \frac{\operatorname{Var}(u)}{\operatorname{Var}(\tilde{E})}
\end{aligned}
$$

onde a primeira igualdade resulta do fato de $u$ e $X$ serem ortogonais.

Esta metodologia tem sido amplamente utilizada na literatura para abordar diversos temas como o efeito das escolas públicas comparadas a privadas sobre o desempenho acadêmico dos alunos na Índia (Goyal 2009) e no Brasil (Cavalcanti et al. 2010), o efeito de domicílios que foram expostos a guerra sobre a probabilidade de frequentar reuniões na comunidade e sobre a probabilidade de votar em Serra Leoa (Bellows \& Miguel 2009), o efeito sobre o desempenho acadêmico dos alunos quando o professor pertence ou não ao sindicato de professores (Kingdon \& Teal 2010) e o efeito da cateterização do coração direito (Swan-Ganz Catheterization) sobre a probabilidade de morte de pacientes na Unidade de Tratamento Intensiva (UTI) (Altonji et al. 2008).

Na próxima seção são apresentados os resultados quanto aos determinantes da evasão assim como são discutidos os efeitos das escolas públicas e privadas e dos cursinhos pré-vestibulares.

\section{Resultados}

Os coeficientes estimados a partir da equação 1 são apresentados na Tabela 3. Foram consideradas cinco especificações distintas. Em todas as especificações foi incluído controle para alunos que entraram na universidade na segunda entrada e controle para o ano de entrada dos alunos. A partir da especificação da coluna (2), também foram incluídos efeitos fixos para os cursos em que os alunos estavam matriculados.

Na coluna (1) foi incluída apenas a nota do estudante no vestibular. Dado o coeficiente negativo e significante, obtém-se que alunos que entraram com notas menores no vestibular apresentam maior evasão quando comparados a alunos que tiveram desempenho mais satisfatório no vestibular, ou, dito de outra forma, quanto maior a barreira à entrada, que reflete diretamente a concorrência para ingressar nos cursos, menor o número de estudantes evadidos. A Figura 1 mostra a nota mínima de entrada em cada curso e o índice de evasão. Pode-se observar que há uma relação inversa entre nota mínima de entrada e evasão. A figura também mostra que os cursos da área de saúde têm índices de evasão baixos e notas mínimas de entrada relativamente altas enquanto que cursos da área de exatas tem evasão alta e notas de entrada bastante baixas.

Na coluna (2) adicionaram-se efeitos fixos para cada curso oferecido pela UFPE. Observa-se que, controlando-se para os cursos, alunos que obtém notas maiores no vestibular apresentam, em média, maior evasão quando comparados a alunos do mesmo curso com desempenho inferior no exame de entrada, 


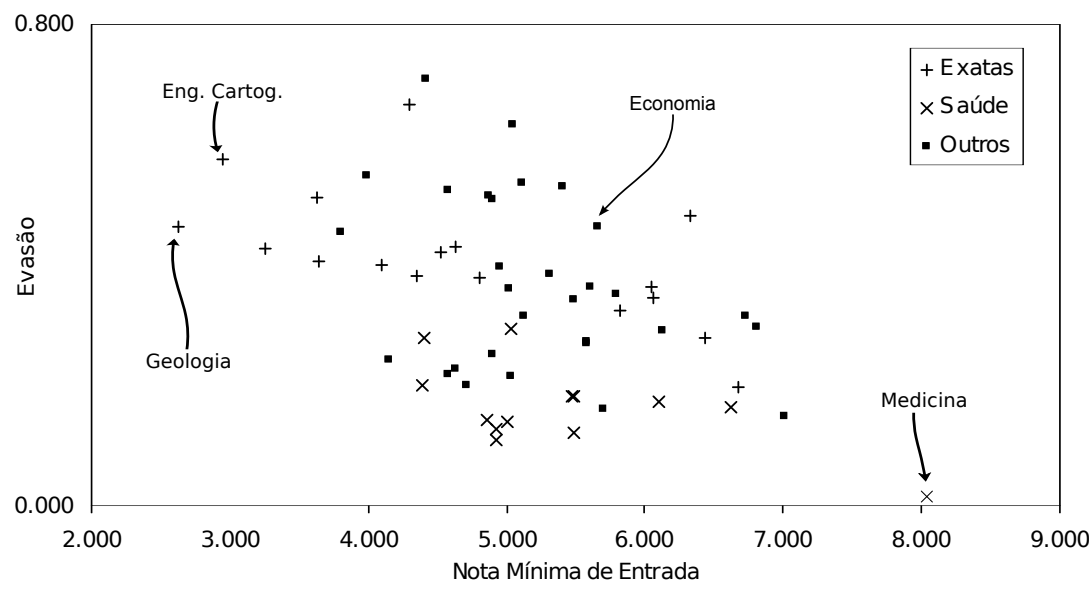

Figura 1: Evasão e Nota Mínima de Entrada

resultado bastante distinto do observado na literatura. Deve-se lembrar que o que se estima é uma correlação entre nota de entrada e evasão e não um efeito causal, portanto não se busca dar uma interpretação causal ao coeficiente estimado. Porém, aos olhos da instituição que busca formular políticas visando a redução da evasão, a correlação é um dado importante, pois traça o perfil do estudante mais propenso a evadir-se.O efeito causal nesse caso não seria de grande importância visto que políticas que buscam reduzir evasão através da mudança na nota de entrada não fariam qualquer sentido.

Na coluna (3) adicionou-se variáveis que dizem respeito à educação dos pais e à renda familiar. Com relação à educação dos pais, são adicionadas três variáveis dummy onde a categoria excluída são famílias cujos pais são analfabetos. Com relação à renda, são adicionadas quatro dummies sendo a categoria excluída famílias cuja renda é inferior a cinco salários mínimos. Uma opção seria transformar as variáveis de renda e educação em uma única variável onde as dummies de educação seriam transformadas em anos de escolaridade, para educação dos pais, por exemplo. Neste caso, seria obtido um único coeficiente. Porém, optou-se pela não introdução da linearidade nas variáveis dado que os efeitos são não lineares para cada categoria, como pode ser observado na Tabela 3.

Os resultados mostram que a educação dos pais não tem correlação alguma com evasão dos alunos uma vez que se controla pela renda familiar. Mesmo se renda for excluída da equação de estimação, os coeficientes de educação dos pais pouco se alteram. Com relação à renda, o único coeficiente significante é para alunos cuja renda familiar é superior a 20 salários mínimos. Esta correlação positiva possivelmente resulta de dois fatores: pais mais educados têm em geral maior compreensão quanto à necessidade dos filhos escolherem uma carreira que mais se adeque aos seus desejos; e pais mais instruídos têm maior renda, que os permite arcar com um período de estudo preparatório para que seus filhos tentem um outro vestibular. Este resultado difere bastante de resultados apresentados para universidades americanas e britânicas.

Na coluna (4) adicionou-se a média que o estudante obteve nos cursos do primeiro semestre na universidade. A inclusão desta variável fortalece ainda mais a correlação da nota no vestibular com evasão. Com relação à média do primeiro período, esta é negativamente correlacionada com evasão uma vez 
que se controla para nota de entrada, background familiar e curso matriculado. Este resultado destaca que o desestímulo com relação a escolha do curso e/ou a dificuldade de acompanhar o mesmo já se reflete no primeiro semestre. ${ }^{11}$

$\mathrm{Na}$ coluna (5) são adicionadas variáveis que dizem respeito a características dos indivíduos como gênero, idade, se o estudante é casado, se mora na Região Metropolitana do Recife - RMR, o número de vestibulares realizados antes da admissão, ${ }^{12}$ se cursou o ensino fundamental e médio em escolas públicas, se já cursou ensino superior anteriormente e se o aluno respondeu estar decidido quanto à escolha do curso no momento da realização do vestibular.

Com relação ao gênero, os resultados mostram que mulheres têm em média menor probabilidade de evasão. Com relação aos coeficientes estimados para idade e número de vestibulares realizados, não se pode, entretanto, dar uma interpretação causal ao efeito. Sampaio et al. (2011) e Sampaio (2009) apresentam extensa discussão sobre os problemas causados pelas variáveis omitidas na identificação do efeito da idade sobre desempenho acadêmico e evasão escolar, respectivamente. $\mathrm{O}$ argumento baseia-se no fato de que alunos menos hábeis tendem a entrar mais velhos na universidade, dado que estes têm, possivelmente, maior probabilidade de reprovação ao longo do ensino fundamental e médio ${ }^{13}$. Neste caso, estimando o efeito de idade sobre evasão obtém-se que alunos mais velhos têm maior probabilidade de evasão, ${ }^{14}$ mas não por que são mais velhos e sim por que são menos hábeis. Sampaio (2009), usando variáveis instrumentais para isolar a influência de variáveis não-observáveis sobre idade, mostra que o efeito causal é na realidade positivo, i.e., quanto mais velho menor é a probabilidade de evasão escolar. O mesmo argumento serve para número de vestibulares prestados até a admissão na universidade, uma vez que estudantes mais hábeis tendem a realizar menor número de vestibulares até aceitação do que estudantes menos hábeis.

Com relação a estar casado, os resultados mostram que alunos que entraram na universidade casados apresentam maior probabilidade de evasão. Optou-se também pela inclusão de uma variável multiplicativa entre gênero e se o estudante estava casado ou não, o que vai permitir captar diferenças do impacto de estar casado sobre mulheres e homens. Neste caso, pode-se observar que não há efeito algum de estar casado sobre a probabilidade de evasão para mulheres. Com relação ao tipo de ensino, os resultados mostram que alunos oriundos do sistema público de ensino parecem não apresentar índice de evasão maior que alunos oriundos do ensino privado. Por fim, alunos que estavam matriculados em outro curso no ensino superior apresentam maior índice de evasão e alunos que declararam estar decididos quanto a escolha do

\footnotetext{
${ }^{11}$ Ver Light \& Strayer (2000) sobre a interação entre habilidade e qualidade do curso e sua consequência sob a probabilidade de obtenção do diploma e Stinebrickner \& Stinebrickner (2009) sobre habilidade acadêmica esperada e realizada (após inicio do curso) sob a probabilidade de evasão.

${ }^{12}$ Considerou-se também uma especificação semelhante à coluna (5) da Tabela 2, porém incluindo-se somente alunos que entraram pela primeira vez na universidade. O resultado mantém-se exatamente o mesmo, isto é, a correlação estimada foi de .069 (.020), significante a $1 \%$.

${ }^{13}$ Ver Elder \& Lubotsky (2009) e McEwan \& Shapiro (2008) para evidencias sobre idade e retenção escolar no ensino fundamental americano

${ }^{14} \mathrm{O}$ coeficiente de idade na Tabela 2 não é estatisticamente diferente de zero. Porém, se for incluído um termo ao quadrado, pode-se mostrar que alunos até 30 anos apresentam correlação positiva com evasão e alunos mais velhos (idade maior que 30 anos) apresentam correlação negativa. Isso faz com que o coeficiente estimado para a variável idade seja zero.
} 
curso apresentaram menores índices de evasão.

Dado que o principal coeficiente de interesse é a estimação da correlação entre nota de entrada e evasão, parece interessante investigar como esta varia em função da nota mínima de entrada. Isto é, pode ser o caso de cursos que tem nota de entrada baixa e, portanto, apresentam maior variância nas notas dos aprovados, apresentam maior evasão entre os alunos com notas mais altas, e cursos que apresentam nota de entrada mais alta apresentam menor ou mesma probabilidade de evasão entre os aprovados. ${ }^{15}$ Neste caso, o resultado obtido na coluna (5) da Tabela 3 seria maior que 0.066 para os cursos com menores notas de entrada (maior variância nas notas de entrada) e menor que 0.066 para cursos com maiores notas de entrada. ${ }^{16}$ Na Tabela 4 pode-se observar que este não é o caso, i.e., a relação entre nota do vestibular e evasão parece ser a mesma entre os cursos mais e menos concorridos.

Tabela 3: Efeitos Marginais - Estimados a partir do modelo probit

\begin{tabular}{|c|c|c|c|c|c|}
\hline Variáveis & $(1)$ & $(2)$ & (3) & $(4)$ & (5) \\
\hline Vestibular & $\begin{array}{c}-.041^{* * *} \\
(.005)\end{array}$ & $\begin{array}{l}.026^{* * *} \\
(.010)\end{array}$ & $\begin{array}{l}.018^{* * *} \\
(.010)\end{array}$ & $\begin{array}{l}.069^{* * *} \\
(.011)\end{array}$ & $\begin{array}{l}.066^{* * *} \\
(.011)\end{array}$ \\
\hline \multicolumn{6}{|l|}{ Educação dos Pais } \\
\hline$\cdot 1^{\circ} \mathrm{Grau}$ Completo & & & $\begin{array}{l}.024 \\
(.029)\end{array}$ & $\begin{array}{l}.039 \\
(.030)\end{array}$ & $\begin{array}{l}.068^{* *} \\
(.034)\end{array}$ \\
\hline \multicolumn{2}{|l|}{$\cdot 2^{\circ} \mathrm{Grau}$ Completo } & & $\begin{array}{r}-.005 \\
(.024)\end{array}$ & $\begin{array}{l}.003 \\
(.025)\end{array}$ & $\begin{array}{l}.051^{*} \\
(.030)\end{array}$ \\
\hline \multicolumn{3}{|l|}{ - Superior Completo } & $\begin{array}{l}.012 \\
(.025)\end{array}$ & $\begin{array}{l}.025 \\
(.025)\end{array}$ & $\begin{array}{l}.073^{\star *} \\
(.030)\end{array}$ \\
\hline \multicolumn{6}{|c|}{ Renda Familiar (Salário Mínimo) } \\
\hline 5 a 10 & & & $\begin{array}{l}.010 \\
(.014)\end{array}$ & $\begin{array}{r}-.002 \\
(.014)\end{array}$ & $\begin{array}{r}-.014 \\
(.015)\end{array}$ \\
\hline$\cdot 11$ a 15 & & & $\begin{array}{l}.043^{* *} \\
(.020)\end{array}$ & $\begin{array}{l}.025 \\
(.020)\end{array}$ & $\begin{array}{r}-.003 \\
(.020)\end{array}$ \\
\hline$\cdot 16$ a 20 & & & $\begin{array}{l}.0500^{* *} \\
(.020)\end{array}$ & $\begin{array}{l}.029 \\
(.020)\end{array}$ & $\begin{array}{r}-.004 \\
(.020)\end{array}$ \\
\hline$\cdot>20$ & & & $\begin{array}{l}.106^{* * *} \\
(.024)\end{array}$ & $\begin{array}{l}.085^{* * *} \\
(.024)\end{array}$ & $\begin{array}{l}.060^{* * *} \\
(.024)\end{array}$ \\
\hline \multicolumn{5}{|l|}{ Gênero (feminino=1) } & $\begin{array}{c}-.049^{* * *} \\
(.013)\end{array}$ \\
\hline \multicolumn{5}{|l|}{ Idade } & $\begin{array}{l}.002 \\
(.002)\end{array}$ \\
\hline \multicolumn{5}{|l|}{ Casado } & $\begin{array}{l}.121^{* * *} \\
(.040)\end{array}$ \\
\hline \multicolumn{5}{|l|}{ Gênero $\times$ Casado } & $\begin{array}{c}-.123^{* * *} \\
(.050)\end{array}$ \\
\hline \multicolumn{3}{|l|}{ Região Metropolitana } & & & $\begin{array}{l}.038^{* *} \\
(.018)\end{array}$ \\
\hline \multicolumn{6}{|c|}{$\begin{array}{l}\text { Nota: } \text { Desvio Padrão apresentado entre parênteses. A variável } \\
\text { dependente assume valor igual a } 1 \text { para alunos que optaram } \\
\text { pela evasão nos primeiros dois anos de curso. Todas as } \\
\text { regressões incluem dummies para ano de entrada assim como } \\
\text { dummies para alunos que entraram na segundo entrada. }{ }^{* *} \\
\text { indica } \mathrm{p}<0.01,{ }^{* *} \mathrm{p}<0.05 \mathrm{e}^{*} \mathrm{p}<0.10 \text {. }\end{array}$} \\
\hline
\end{tabular}

\footnotetext{
${ }^{15}$ Uma hipótese seria considerar que o nível de cobrança dos professores é determinado pelo nível do aluno médio da turma. Neste caso, se há grande variação entre o nível dos alunos na turma, os melhores poderiam optar pela evasão em decorrência de um baixo grau de cobrança.

${ }^{16}$ Os autores agradecem a um dos pareceristas por levantar este ponto.
} 
Tabela 3: Efeitos Marginais - Estimados a partir do modelo probit (continued)

\begin{tabular}{|c|c|c|c|c|c|}
\hline Variáveis & (1) & (2) & (3) & (4) & (5) \\
\hline \multicolumn{6}{|l|}{ Número de Vestibulares } \\
\hline$\cdot 1$ & & & & & $\begin{array}{c}-.031^{* *} \\
(.014)\end{array}$ \\
\hline$\cdot 2$ & & & & & $\begin{array}{c}-.033^{* *} \\
(.017)\end{array}$ \\
\hline$\cdot 3$ & & & & & $\begin{array}{c}-.057^{* *} \\
(.021)\end{array}$ \\
\hline$\cdot>3$ & & & & & $\begin{array}{c}-.037^{* *} \\
(.026)\end{array}$ \\
\hline \multicolumn{6}{|l|}{ Escola Pública } \\
\hline - Ensino Fundamental & & & & & $\begin{array}{l}.006 \\
(.021)\end{array}$ \\
\hline - Ensino Médio & & & & & $\begin{array}{l}.001 \\
(.017)\end{array}$ \\
\hline Cursa Ensino Superior & & & & & $\begin{array}{l}.175^{* * *} \\
(.019)\end{array}$ \\
\hline Decidido Quanto ao Curso & & & & & $\begin{array}{c}-.033^{* *} \\
(.016)\end{array}$ \\
\hline Segunda Entrada & $\begin{array}{c}-.124^{* * *} \\
(.010)\end{array}$ & $\begin{array}{l}-.044^{* * *} \\
(.013)\end{array}$ & $\begin{array}{l}-.041^{* * *} \\
(.013)\end{array}$ & $\begin{array}{l}-.041^{* * *} \\
(.013)\end{array}$ & $\begin{array}{l}-.041^{* * *} \\
(.013)\end{array}$ \\
\hline Média $1^{\circ}$ Semestre & & & & $\begin{array}{l}-.091^{* * *} \\
(.005)\end{array}$ & $\begin{array}{l}{ }^{*}-.091^{* * *} \\
(.005)\end{array}$ \\
\hline Cursos (Efeito Fixo) & NÃO & SIM & SIM & SIM & SIM \\
\hline Pseudo $R^{2}$ & $\begin{array}{l}.025 \\
(.005)\end{array}$ & .107 & .111 & .148 & .169 \\
\hline \multicolumn{6}{|c|}{$\mathrm{N}=7,582$} \\
\hline $\begin{array}{l}\text { Desvio Padrão apreser } \\
\text { dependente assume v } \\
\text { evasão nos primeiros } \\
\text { incluem dummies par } \\
\text { para alunos que entra } \\
* \star \mathrm{p}<0.05 \mathrm{e}^{*} \mathrm{p}<0.10 .\end{array}$ & $\begin{array}{l}\text { ntado en } \\
\text { alor igua } \\
\text { dois ano } \\
\text { ra ano de } \\
\text { aram na s }\end{array}$ & $\begin{array}{l}\text { tre parên } \\
\text { l a } 1 \text { para } \\
\text { s de curso } \\
\text { entrada } \\
\text { segundo e }\end{array}$ & $\begin{array}{l}\text { nteses. A } \\
\text { a alunos } \\
\text { o. Todas } \\
\text { assim cor } \\
\text { entrada.** }\end{array}$ & $\begin{array}{l}\text { variável } \\
\text { que optar } \\
\text { as regres } \\
\text { mo dumr } \\
* * * \text { indica }\end{array}$ & $\begin{array}{l}\text { aram pela } \\
\text { ssões } \\
\text { amies } \\
\mathrm{p}<0.01\end{array}$ \\
\hline
\end{tabular}

\subsection{Os efeitos Escola Pública e Cursinho Pré-vestibular}

Nesta seção são discutidos os efeitos de se estudar em escolas privadas ou públicas e de participar de cursinhos pré-vestibulares. O efeito das escolas públicas sobre o desempenho dos alunos foi estimado por Cavalcanti et al. (2010), que utilizaram a mesma base de dados usada neste artigo. Os autores chegaram a conclusão de que alunos que estudaram em escolas públicas tem em media desempenho 4.2, 17\% inferior a alunos que estudaram em escolas privadas. Este resultado se mostrou robusto ao teste proposto por Altonji, E. \& Taber (2005), assim como, à inclusão de variável proxy para habilidade do estudante (exame do ENEM).

Outro resultado importante é que, como esperado, há alta correlação entre renda familiar e probabilidade do aluno se matricular no ensino público. Nesse sentido, e este é um dos principais pontos enfatizados por Cavalcanti et al. (2010), alunos oriundos de famílias de baixa renda enfrentam grandes barreiras para serem aceitos nas universidades brasileiras e, quando são, é para cursos de menor concorrência com baixo retorno salarial futuro. 
Tabela 4: Nota Mínima de Entrada e a Relação Vestibular vs. Evasão

\begin{tabular}{|c|c|c|}
\hline Variáveis & Nota mínima $<5.4$ & Nota mínima $>=5.4$ \\
\hline Vestibular & $\begin{array}{l}.061^{* * *} \\
(.014)\end{array}$ & $\begin{array}{l}.081^{* * *} \\
(.018)\end{array}$ \\
\hline $\mathrm{N}=$ & 3,529 & 4,053 \\
\hline
\end{tabular}

Com relação aos cursinhos pré-vestibulares, a Tabela 5 apresenta dois resultados importantes. O primeiro deles é apresentado na coluna (1), onde é estimada correlação entre estar matriculado em cursinhos e desempenho no vestibular. A correlação se mostra positiva, ou seja, as notas dos alunos que fizeram cursinhos são quase 0.2 desvios padrões maiores que as notas dos alunos que não fizeram cursinhos. Como dito acima, esta correlação representa não só o efeito dos cursinhos, mas também o efeito de variáveis não observáveis como habilidade dos indivíduos. Na tentativa de dar interpretação causal a correlação estimada, utilizou-se o teste de Altonji, E. \& Taber (2005), cujo viés estimado foi de -0.081 . Este resultado mostra que os cursinhos têm efeito positivo e relativamente grande no desempenho dos alunos no vestibular. ${ }^{17}$

Na coluna (2) estima-se um modelo linear de probabilidade em que a variável dependente assume valor igual a 1 para alunos que ingressaram em cursinhos pré-vestibulares e 0 , caso contrário. Pode-se observar que renda e presença em aulas particulares estão altamente correlacionadas. Este resultado sugere que alunos oriundos de famílias de maior renda têm maiores possibilidades quanto ao acesso a recursos adicionais, como aulas particulares, que tem grande impacto em seu desempenho escolar e, por consequência, em sua probabilidade de ingresso no ensino superior.

\subsection{Quem refaz vestibular após optar pela evasão?}

Uma vez que este trabalho busca não só tentar melhor compreender o fenômeno da evasão dos estudantes universitários, mas também entender que mecanismo está por trás desta decisão, surge a necessidade de se olhar o perfil dos alunos que decidiram prestar novo vestibular dado que no período anterior estes optaram pela evasão (aproximadamente $34 \%$ dos alunos que optaram pela evasão são observados no ano seguinte prestando novo vestibular).

Na Tabela 6 são apresentados os resultados. O modelo linear de probabilidade tem como variável dependente uma dummy que assume valor igual a 1 para alunos que são observados no vestibular seguinte à decisão de evasão e zero para alunos que não são observados após decisão de evasão. Um primeiro resultado interessante é que a nota de entrada que o aluno obteve no vestibular prestado para o curso que foi interrompido pela decisão de evasão apresenta correlação positiva com a probabilidade de realizar novo vestibular.

\footnotetext{
${ }^{17}$ Para se ter uma ideia da magnitude do Angrist \& Lavy (1999) e Rouse (1998) estimam que reduções no numero de alunos presentes em sala tem efeito de 0.18-0.29 e 0.08-0.12 desvios padrões, respectivamente, sobre o desempenho acadêmico dos alunos.
} 
Tabela 5: Cursinhos pré-vestibular, Nota de entrada e Renda familiar

\begin{tabular}{|c|c|c|}
\hline Variáveis & $(1)$ & (2) \\
\hline Cursinhos & $\begin{array}{l}.198^{* * *} \\
(.012)\end{array}$ & \\
\hline \multicolumn{3}{|c|}{ Renda Familiar (Salário Mínimo) } \\
\hline \multicolumn{2}{|c|}{5 a 10} & $\begin{array}{l}.015^{* * *} \\
(.006)\end{array}$ \\
\hline \multicolumn{2}{|l|}{$\cdot 11$ a 15} & $\begin{array}{l}.071^{* * *} \\
.008)\end{array}$ \\
\hline \multicolumn{2}{|l|}{$\cdot 16$ a 20} & $\begin{array}{l}.106^{* * *} \\
(.010)\end{array}$ \\
\hline \multicolumn{2}{|l|}{$\cdot>20$} & $\begin{array}{l}.144^{* * *} \\
(.009)\end{array}$ \\
\hline Características Pessoais & SIM & SIM \\
\hline Cursos (Efeito Fixo) & SIM & SIM \\
\hline Viés Estimado & -.081 & \\
\hline \multicolumn{3}{|c|}{$\begin{array}{l}\text { Nota: } \text { Desvio Padrão apresentado entre parênteses. As } \\
\text { estimações foram feitas utilizando-se todos os } \\
\text { alunos prestando vestibular para a UFPE e não } \\
\text { somente aqueles que foram aceitos. A variável } \\
\text { dependente na coluna } 1 \text { é o desempenho } \\
\text { acadêmico normalizado dos alunos. Na coluna } 2 \text { a } \\
\text { variável dependente é uma dummy que assume } \\
\text { valor igual a } 1 \text { para alunos que se matricularam em } \\
\text { cursinhos pré-vestibulares e zero para os que não } \\
\text { se matricularam. Características pessoas incluem } \\
\text { gênero, idade, entre outras reportadas na Tabela } 3 . \\
\text { ** } \\
\text { indica p }<0.01 \text {. }\end{array}$} \\
\hline
\end{tabular}

Ou seja, dentre os alunos que optaram pela evasão, alunos com desempenho de entrada melhor estão tentando novo vestibular no período após a decisão. Este resultado corrobora a hipótese levantada acima de que alunos mais "hábeis", uma vez que o matching com a carreira não é bem sucedido, optam pela evasão para tentar novo vestibular em busca de um melhor matching.

Com relação à educação dos pais e renda familiar, dentre os alunos que optaram pela evasão, os mais ricos tendem a fazer novo vestibular na Universidade Federal de Pernambuco, enquanto que os mais pobres não são observados no ano seguinte à decisão de evasão. É importante salientar também que aproximadamente $64 \%$ dos alunos que optaram por tentar nova carreira tiveram acesso a cursinhos pré-vestibulares ao longo do ano. Ou seja, renda tem papel fundamental não só por proporcionar aos alunos mais ricos melhores condições de estudo (como acesso a escolas privadas, a Internet, a cursinhos pré-vestibulares, entre outros), mas também por possibilitar ao aluno maior oportunidade de escolha, através de tentativas, da melhor carreira que se adeque às suas aptidões.

\section{Conclusões e Implicações}

Este artigo tem como objetivo principal buscar melhor compreensão da decisão de evasão tomada por estudantes universitários, assunto que tem recebido pouca atenção dos pesquisadores da área no Brasil, utilizando-se dados de alu- 
Tabela 6: Nota de entrada, Educação dos pais, Renda familiar e a decisao de fazer novo vestibular

\begin{tabular}{|c|c|c|c|c|}
\hline Variáveis & (1) & $(2)$ & (3) & $(4)$ \\
\hline Nota de Entrada & $\begin{array}{l}.068^{* * *} \\
(.013)\end{array}$ & $\begin{array}{l}.128^{* * *} \\
(.020)\end{array}$ & $\begin{array}{l}.130^{* * *} \\
(.020)\end{array}$ & $\begin{array}{l}.132^{* * *} \\
(.020)\end{array}$ \\
\hline \multicolumn{5}{|l|}{ Educação dos Pais } \\
\hline$\cdot 1^{\circ} \mathrm{Grau}$ Completo & & & $\begin{array}{l}.186^{* * *} \\
(.062)\end{array}$ & $\begin{array}{l}.208^{* * *} \\
(.061)\end{array}$ \\
\hline$\cdot 2^{\circ} \mathrm{Grau}$ Completo & & & $.119^{* * *}$ & $.149^{* * *}$ \\
\hline - Superior Completo & & & $.078^{*}$ & $.141^{* * *}$ \\
\hline \multicolumn{5}{|c|}{ Renda Familiar (Salário Mínimo) } \\
\hline$\cdot 5$ a 10 & & & & $\begin{array}{l}.073^{* * *} \\
(.033)\end{array}$ \\
\hline$\cdot 11$ a 15 & & & & $\begin{array}{l}.141^{* * *} \\
(.042)\end{array}$ \\
\hline$\cdot 16$ a 20 & & & & $\begin{array}{l}.096^{*} \\
(.050)\end{array}$ \\
\hline$\cdot>20$ & & & & $\begin{array}{l}.114^{* *} \\
.045)\end{array}$ \\
\hline Características Pessoais & $\mathrm{NO}$ & YES & YES & YES \\
\hline Cursos (Efeito Fixo) & NO & YES & YES & YES \\
\hline
\end{tabular}

nos matriculados nos cursos oferecidos pela Universidade Federal de Pernambuco para os anos de 2003 e 2004. Maior ênfase é dada à relação entre renda e evasão e à relação entre nota de entrada no vestibular e evasão. Atenção também é dada a alguns determinantes do sucesso no exame do vestibular, como o efeito da escola pública e de aulas particulares (cursinhos), que são bastante populares entre alunos oriundos de famílias de maior renda.

Os resultados mostram que há correlação negativa entre nota de entrada e evasão escolar, resultado consagrado na literatura. Porém, uma vez que são adicionados efeitos fixos para os cursos, o sinal da correlação se inverte, podendo-se inferir que os evadidos, em média, são os melhores alunos em cada curso. Na tentativa de entender os mecanismos que geram este resultado surpreendente, levantou-se a seguinte hipótese: dado o reconhecimento da escolha da carreira equivocada, alunos com maior renda e, em consequência, melhor desempenho (uma vez que a nota reflete em parte o background familiar, principalmente educação e renda) estão optando pela evasão não pela escolha da entrada no mercado de trabalho, mas sim pela oportunidade que lhes é dada (através do suporte familiar) de tentar uma nova carreira.

Para fornecer evidências a hipótese descrita acima, buscou-se primeiro estimar o diferencial de desempenho entre escolas públicas e privadas e o efeito dos cursinhos pré-vestibulares. Em seguida, buscou-se traçar o perfil daqueles alunos que, após se evadirem, prestaram novo vestibular. Por um lado, entender o efeito escola pública e o efeito cursinho é importante por que a escola pública, se tiver impacto negativo sobre o desempenho, impõe grande barreira à entrada dos alunos oriundos de famílias mais pobres; com relação aos cursinhos pré-vestibulares, estes funcionam como mais um diferencial dos 
alunos oriundos de famílias mais ricas na realização do primeiro vestibular assim como, para os alunos que se evadiram, na realização do segundo vestibular. De outro lado, é importante compreender o perfil dos alunos que optam pela evasão para nova tentativa, pois pode ser informativo quanto a influencia do background familiar, por exemplo.

Os resultados mostram que, como esperado, as escolas públicas tem impacto negativo e os cursinhos têm impacto positivo sobre o desempenho dos alunos. Renda tem relação positiva com matrícula em escolas privadas assim como com matrícula em cursinhos pré-vestibulares. Com relação aos alunos que prestam vestibular no ano seguinte à decisão de evasão, estes têm maior nota de entrada no vestibular anterior, maior renda e pais mais educados em comparação aos alunos que não são observados novamente. Ou seja, renda tem papel fundamental não só por proporcionar aos alunos mais ricos melhores condições de estudo (como acesso a escolas privadas e a cursinhos prévestibulares), mas também por possibilitar ao aluno maior oportunidade de escolha, através de tentativas, da carreira que melhor se adeque as suas aptidões.

A evasão decorrente da desistência de um curso por outro se deve em parte a rigidez curricular. É possível que em se adotando uma maior flexibilidade curricular, como ocorre em diversos paises, o aluno possa acomodar melhor seus interesses. Essa flexibilidade atende a todos os alunos: os melhor dotados e com renda mais elevada por evitar o custo e tempo de um novo vestibular e os de menor renda por permitir um melhor ajuste a seus interesses; atende também as instituições pelo potencial de redução da evasão. Santos \& Kassouf (2008), por exemplo, estima que a imposição de restrições quanto à mudança de curso (majors) para alunos universitários americanos resultaria em perdas significativas de bem-estar.

A nota obtida no primeiro período é inversamente relacionada à evasão. Este resultado corresponde ao encontrado em outros trabalhos. Confirma que o desestímulo com o curso e/ou a dificuldade de acompanhá-lo se apresenta desde o primeiro período. Esta é mais uma indicação da falta de conhecimento do curso e das carreiras, o que leva muitos alunos a prestarem vestibular com percepções equivocadas sobre os cursos (ou convicções sobre a escolha feita). Recorde-se que os estudantes que se declararam decididos quanto ao curso escolhido tem menor probabilidade de evasão. Não obstante, a flexibilização curricular atenderia a todos, mas predominantemente aos que possuem menor background familiar. Sob esse aspecto, inclusive, pode trazer redução das desigualdades de oportunidades educacionais traduzidas em fluxos futuros de renda.

Outra questão interessante diz respeito às universidades públicas federais serem gratuitas. Como discutido acima, alunos oriundos de famílias com maior renda apresentam menor "custo", uma vez que a decisão é refazer o vestibular em busca de novo curso, do que alunos de famílias com menor renda, o que seria justificado pelo coeficiente positivo obtido para famílias cuja renda é superior a 20 salários mínimos anuais. Ou seja, a possibilidade de se ter um bom matching com a carreira escolhida aumenta com a alocação inicial de riqueza o que, possivelmente, desfavorece a redução da desigualdade. Neste artigo não se busca tirar qualquer conclusão referente ao sistema de admissão e financiamento das instituições de ensino superior. Porém, as evidencias empíricas fornecidas, apesar de preliminares, mostram que há elevada evasão, principalmente dos melhores alunos, e apontam na direção de que o desenho 
atual do sistema favorece alunos de famílias mais ricas. No entanto, mais estudos são necessários para que se possa apontar novos caminhos, como quotas, reforço do ensino público secundário, entre outras políticas, que ajudem a se superar as desigualdades observadas entre alunos de escolas públicas e privadas, alunos com acesso a cursinhos e alunos favorecidos pela maior renda e educação dos pais comparativamente aos destituídos dessas condições.

Este trabalho adentrou uma área pouco analisada na economia da educação brasileira e como tal desvendou algumas pistas, mas há ainda uma longa estrada a percorrer no sentido da equalização das oportunidades de ensino, responsável destacado pela persistente desigualdade de renda no Brasil.

\section{Agradecimentos}

Os autores agradecem sugestões e comentários de pareceristas anônimos, do editor associado Irineu de Carvalho Filho e de participantes do XV Encontro Regional de Economia - ANPEC Nordeste. Breno Sampaio agradece apoio financeiro do Center for Latin American and Caribbean Studies (CLACS) da University of Illinois at Urbana-Champaign através do Tinker Field Research Grant. Yony Sampaio agradece apoio financeiro do CNPq.

\section{Referências Bibliográficas}

Ai, C., N. E. C. (2003), 'Interaction terms in logit and probit models', Economics Letters 80, 123-129.

Altonji, J. G., E, E. T. \& Taber, C. R. (2008), 'Using selection on observed variables to assess bias from unobservables when evaluating swan-ganz catheterization.', American Economic Review: Papers E Proceedings 98(2), 345-350.

Altonji, J. G., E., E. \& Taber, C. R. (2005), 'Selection on observed and unobserved variables: assessing the effectiveness of catholic schools', Journal of Political Economy 113(1), 151-184.

Altonji, J. G., Elder, T. E. \& Taber, C. R. (2005), 'An evaluation of instrumental variable strategies for estimating the effects of catholic schooling', Journal of Human Resources 40(4), 791-821.

Angrist, J. \& Lavy, V. (1999), 'Using maimonides' rule to estimate the effect of class size on scholastic achievement', Quarterly Journal of Economics 114(2), 533-575.

Arulampalam, W., Naylor, R. A. \& Smith, J. P. (2004), 'A hazard model of the probability of medical school drop-out in the uk', Journal Of The Royal Statistical Society Series A 167(1), 157-178.

Ashenfelter, O. \& Rouse, C. (1998), 'Income, schooling, and ability: Evidence from a new sample of identical twins', Quarterly Journal of Economics 113(1), 253-284.

Becker, G. S. (1964), Human capital: a theoretical and empirical analysis with special reference to education, Columbia University Press, New York.

Behrman, J. R., Pollack, R. A. \& Taubman, P. (1982), 'Parental preferences and provision for progeny', Journal of Political Economy 90(1), 52-73. 
Behrman, J. R., Rosenzweig, M. R. \& Taubman, P. (1994), 'Endowments and the allocation of schooling in the family and in the marriage market: The twins experiment.', Journal of Political Economy 102(6), 1131-1174.

Bellows, J. \& Miguel, E. (2009), 'War and local collective action in sierra leone', Journal of Public Economics 93(11-12), 1144-1157.

Blanchfield, W. C. (1972), 'College dropout identification: An economic analysis', Journal of Human Resources 7(4), 540-544.

Bourguignon, F., Ferreira, F. \& Menéndez, M. (2007), 'Inequality of opportunity in Brazil', Review of Income $\mathcal{E}$ Wealth 53(4), 585-618.

Bradley, S. \& Lenton, P. (2007), 'Dropping out of post-compulsory education in the uk: an analysis of determinants and outcomes', Journal of Population Economics 20(2), 299-328.

Cavalcanti, T., Guimarães, J. \& Sampaio, B. (2007), Quantitative evidences on inequality of opportunities in brazil, in 'Anais do XXIX Encontro Brasileiro de Econometria, Recife', Sociedade Brasileira de Econometria.

Cavalcanti, T., Guimarães, J. \& Sampaio, B. (2010), 'Barriers to skill acquisition in Brazil: Public and private school students performance in a public university entrance exam', Quarterly Review of Economics and Finance 50(4), 395-407.

Curi, A. Z. \& de Menezes-Filho, N. A. (2006), A relação entre desempenho escolar e os salarios no Brasil, Working Paper 03, IBMEC, Sao Paulo.

DesJardins, S. L., Ahlburg, D. A. \& McCall, B. P. (1999), 'An event history model of student departure', Economics of Education Review 18(3), 375-390.

Di Pietro, G. (2004), 'The determinants of university dropout in Italy: a bivariate probability model with sample selection', Applied Economics Letters 11(3), 187-191.

Eckstein, Z. \& Wolpin, K. (1999), 'Why youths drop out of high school: The impact of preferences, opportunities, and abilities', Econometrica 67(6), 1295-1339.

Elder, T. \& Lubotsky, D. (2009), 'Kindergarten entrance age and children's achievement: Impacts of state policies, family background, and peers', Journal of Human Resources 44(3), 641-683.

Emilio, D. R., Belluzzo, W. J. \& Alves, D. C. (2004), 'Uma análise econométrica dos determinantes do acesso à Universidade de São Paulo', Pesquisa e Planejamento Economico 34(2), 275-306.

Ferreira, S. \& Veloso, F. (2006), 'Intergenerational mobility of wages in Brazil', Brazilian Review of Econometrics 26(2), 181-211.

Goyal, S. (2009), 'Inside the house of learning: the relative performance of public and private schools in orissa', Education Economics 17, 315-327.

Guimarães, J. F. \& Sampaio, B. (2011), 'Family background and students' achievement on a university entrance exam in brazil', Education Economics, no prelo . 
Guimarães, J. F. \& Sampaio, B. (2007), 'The influence of family background and individual characteristics on entrance tests scores of brazilian university students', Anais do XXXV Encontro Nacional de Economia, Recife, Brasil.

Kingdon, G. \& Teal, F. (2010), 'Teacher unions, teacher pay and student performance in india: A pupil fixed effects approach.', Journal of Development Economics 91(2), 278-288.

Lassibille, G. \& Gómez, L. N. (2008), 'Why do higher education students drop out? evidence from spain', Education Economics 16(1), 89-105.

Light, A. \& Strayer, W. (2000), 'Determinants of college completion: School quality of student ability?', The Journal of Human Resources 35(2), 299-332.

McEwan, P. J. \& Shapiro, J. S. (2008), 'The benefits of delayed primary school enrollment', Journal of Human Resources 41(1), 1-29.

Murtaught, P. A., Burns, L. D. \& Schuster, J. (1999), 'Predicting the retention of university students', Research in Higher Education 40(3), 355-371.

Resende, J. L. (2006), Metas de inflação, câmbio flexível e autonomia de política monetária, Master's thesis, CEDEPLAR/UFMG.

Rothstein, J. M. (2004), 'College performance prediction and the sat', Journal of Econometrics 121(1-2), 297-317.

Rouse, C. E. (1998), 'Private school vouchers and student achievement: An evaluation of the milwaukee parental choice program', Quarterly Journal of Economics 113(2), 553-602.

Sampaio, B. (2009), Too late to change? the effect of age on college students dropout. Mimeo, University of Illinois at Urbana-Champaign.

Sampaio, B., Da Matta, R. A., Ribas, R. P. \& Sampaio, G. (2011), 'The effect of age on college entrance test score and enrollment: A regressoin-discontinuity approach, ssrn working paper series', disponivel em: http://ssrn.com/abstract $=1471686$.

Sampaio, B. \& Guimarães, J. (2009), 'Diferenças de eficiência entre ensino público e privado no Brasil', Revista de Economia Aplicada 13(1), 45-68.

Santos, M. J. \& Kassouf, A. L. (2008), Estudos econômicos das causas da criminalidade no Brasil: Evidências e controvérsias, Technical report, ANPEC.

Stinebrickner, T. \& Stinebrickner, R. (2009), Learning about academic ability and the college drop-out decision, NBER Working Paper 14810, National Bureau of Economic Research.

Veloso, F., Pessoa, S., Henriques, R. \& Giambiagi, F., eds (2009), Educação Básica no Brasil: construindo o pais do futuro, Elsevier, Rio de Janeiro. 